Dr. Eduardo Moore.

\title{
Educación sexual
}

(Conferencia dada en el Club Ocfavio Maira el Sábado 12 de Julio de 1924).

Muy estimables señoras y señores:

O estoy convencido de la utilidad de enseñar por conferencias, porque en ellas un enorme número de los asistentes o no entienden la materia que se dilucida, o se reunen para darse cita. La enseñanza cientifica debe procurarse por una serie espaciada de lecciones: de esta manera se asimila: pero, así como estimo que nunca debe solicitarse un empleo público. ni una comisión. tampoco podemos negarnos, cuando somos solicitados para realizar un bien a los demás. En la Ciencia Sexual, cuando doy conferencias, resuelto a no producir una olensa moral ante la mujer, porque es la que más vale y a la que más respeto, no, no fío en mi improvisación, sino leo lo que he preparado. Por otra parte, no tengo para ello lugar determinado: enseñar, me es igual, sea, en un centro radical o sea en un medio conservador.

Poir eso es por lo que os ruego presteis atención si quereis sacar provecho de lo que os diré. No debeis mirar en mi escrito un discurso literario, porque no lo es: La ciencia viste con sencillez para que los hombres adivinen la verdad. $\mathrm{Y}$ yo vengo a hablaros en nombre de la Ciencia: vengo a deciros verdad. y verdades que algunos no quieren oir ni creer, porque son amargas; pero, vosotros vereis y creereis.

Cuando vamos a los Biógrafos observamos, en las películas, escenas amorosas que empiezan con una intriga social y terminan con una caricia: preludio de la aceptación matrimonial. Los fenómenos emotivos que impresionan a los espectadores. les hace recordar fenómenos semejantes que ellos mismos han experimentado. Estas impresiones, las estudia la ciencia: desde los primeros entusiasmos juveniles, la manera como se desarrollan estas sensaciones y las transfor- 
maciones que van sufriendo con la edad hasta llegar a la formación de los hogares. El hogar, la familia, la base de la sociedad y de la patria, se deriva de esas impresiones normales, analizadas, estudiadas y orientadas por la ciencia.

El matrimonio. la unión entre el hombre y la mujer y el deseado fruto. el hijo. todas estas faces, entran en el mismo estudio. La educación de la niña y del jovencito: el desarrollo de sus instintos normales; las trasgresiones de estos mismos instintos: sus perversiones, todo esto, son capítulos de la Ciencia Sexual.

$\mathrm{Y}$ todavía hay otros capitulos más que se vinculan con las relaciones, aspiraciones y leyes sociales, y con las perturbaciones psíquicas y enfermedades trascendentales.

Ningún asunto preocupa más al hombre que el del sentido de su felicidad y. éste, se basa en la Biologia. Para ser feliz. en el fondo, no se piden sino estas dos cosas: alimentarse y formar un hogar: el sentido de la felicidad, es. entonces, el sentido de la conservación más el sentido de la reproducción. ¿Y qué entendemos por sentido de la conservación?

El sentido de la conservación consiste: en introducirnos alimentos para que el edificio de nuestro organismo, se mantenga sano y con bienestar. Y este organismo ha sido construído única y exclusivamente para alojar a los más nobles de los órganos: los órganos creadores de la vida; aquellos que van a dar inmortalidad a los padres que no mueren nunca, puesto que su vida va a continuar viviendo en sus hijos. La naturaleza quiere que el hijo, continuación de la vida del padre. sea una cadena ininterrumpida que no concluya nunca: muere el individuo: pero sigue la especie.

La Ciencia Sexual es, pues, la más importante de todas las que debemos asimilar; su base es conocer la vida misma, es decir, la Fisiología, cuya inmediata aplicación es la Higiene; conociendo la ciencia de la vida, tenemos base para conocer las alteraciones de ella, es decir, las enfermedades.

En el biógrafo, al que a veces asistimos, vemos a la muchachada de ambos sexos: observarse, hacer amistad, esperarse, simpatizar, flirtear; lo mismo pasa en los teatros y en toda otra reunión social o religiosa; la preocupación constante del hombre es, pues, la mujer y la de ésta el hombre.

Cuando el hombre aspira a tener una posesión, a emanciparse de su familia, la brújula que lo orienta. es el anhelo de buscar una compañera; lo mismo pasa con la niña: se la presenta en sociedad porque en ella se ve ya, orientada por su sexo. que su anhelo es buscar el compañero de su vida.

Domina al hombre, enteramente, la cuestión sexual, desde sus pensamientos idealistas: y a la mujer, desde sus ensueños platónicos, durante toda la vida, y en todos sus actos, desea predominar como político pensando en el pedestal que se elabora el mismo; pero con el propósito de ser dueño (o el esclavo) del ideal de sus amores. Aspira a tener una posesión económica independiente; pero impulsado por los aguijones de Cupido. Anhelan, los humanos: escribir bien, hablar mejor. sobresalir y la meta a donde deben llegar és, siempre, el ideal de sus ensueños: una mujer.

Entonces: las clases en que se divide la sociedad, las luchas cuotidianas para 
adquirir el pan, la abnegación de la madre, la creación y crianza de los hijos, juntas con el amor filial, paternal y fraternal que de estos se deriva y la protección a la familia y el amor patrio, todo, entra en la Ciencia Sexual.

Para conocerla, es menester, conocer primero, las funciones de cada órgano de la vida, es decir: la Fisiología. Es, esta enseñanza, la más necesaria, la más útil. la que inmediatamente debería enseñarse después de saber leer y escribir: ésta, no se enseña entre nosotros. ¿Y por qué? porque ella no produce ni pedestal para su independencia económica; ni temas para los pseudo-literatos y su no enseñanza significa: desorientación, falta de respeto a si mismo, perversiones sexuales, perturbaciones en el matrimonio y autorización de instituciones que, como la prostitución. han sido arrojadas de los paises civilizados.

No enseñar en las Escuelas y Liceos la Fisiología, especialmente las grandes funciones destinadas a crear vida, y la Higiene destinada a preservarse, hacen que sea nuestro país, el que tiene el honor tristísimo, de ir a la cabeza de los pueblos infectados por las más espantosas plagas de enfermedades de trascendencia social.

Si Uds., profundizan la moral, muy pronto reconocerán que la mayoría de los preceptos que ella nos fija son sobre asuntos relacionados con el sexo. La religión católica que convive en nuestros hogares-aunque los jeles no seamos socios de ella, gobierna las almas de sus monjes y de sus vestales, exigiéndoles castidad; la de sus creyentes, vigilando se respeten a sí mismo, es decir, no hagan a solas, actos que no podrán realizarlos, sin un castigo de oprobio y de vergüenzas delante de los demás y cuidando que no triunfen las malas pasiones y las enfermedades que nacen de los vicios sexuales.

La religión santifica el matrimonio, evita el divorcio y la poligamia condena al mal hijo, a la prostituta y al libertino y estimula la formación de las familias y el aumento de los hijos.

La religión musulmana, ofrece su paraiso de vírgenes hermosas, conmina al vicio, al alcohólico y a la infiel. Y señala a sus hijos varones, con la circuncición no sólo como un símbolo religioso racial, sino cuidando que el órgano creador de vida no tenga inflamaciones, ni entorpecimientos en el día destinado a procrear.

Los israelitas, que consideran impuro a cualesquier cruzamiento de sus hijos con otros de otras razas. que tienen el ejemplo de sus castas matronas heroinas del honor, mantienen sus hogares alumbrados con la moral y la pureza de sus mujeres.

Entre los protestantes se cuida de las relaciones sexuales y de la salubridad de los cónyuges, se practica lo dicho sobre los católicos pero no son célibes los sacerdotes ni se estimula la procreación.

La sociedad laica, Uds., yo, queremos a nuestra madre, sin tacha; a nuestras esposas, fieles; a nuestras hijas, púdicas; a nuestras novias, purisimas. ¿La moral, en el fondo. es una disciplina sexual; el problema sexual es un problema moral. La enseñanza de la ciencia que estudiamos es muy vasta.

En los países más adelantados, ante todas las cosas empiezan a interesar 
a los pequeñitos en la Escuela en la enseñanza de la Botánica, en la fecundación de las plantas: a darles explicación amplia sobre todo lo que preguntan; a enseñarles Fisiologia y las grandiosas funciones de la reproducción, antes que se aperciban de su sexo, y antes que las sirvientas y los muy sabidos les abran los ojos con divagaciones eróticas y viciosas. A los once años, deben ya los jóvenes de ambos sexos estar instruídos; pero al alcance de sus limitadas mentalidades de lo que significa su gran rol de creador de una nueva vida, de una hermosa vida, de buenos y sanos ciudadanos que los enorgullezca como el más alto de los honores que puedan recibir en la tierra.

Esta enseñanza, debe empezar a suministrarla la propia madre-la mejor pedagoga-para continuar en la escuela; así, evitariamos: la ignorancia de sus instintos normales, el uso indebido de estas grandes funciones, o. que frutos todavía no maduros, crean que tienen derechos que no les corresponden.

El instinto sexual existe; no podemos, ni negarlo, ni ocultárselo a nuestros hijos: luego. cae en nosotros, la gran responsabilidad de dárselos a conocer; a encauzar esos sentires en un río con riberas de díques sólidos, porque de otra manera, veríamos al río desbordarse en arroyos caudalosos como el libertinaje y las desviaciones sexuales. El instinto sexual es la base de la existencia humana: es el fundamento de la obra más sublime que un hombre puede realizar. Es, él, quien nos incita a las grandes idealidades; entonces, hay que estudiarlo y ésto lo enseña la Ciencia Sexual. Ella nos dice que, todo el que no se somete a las leyes de la Fisiología, no respetándose así mismo, tiene como compañeros: a las perturbaciones mentales, a la tuberculosis y a la tumba: pero. tam. bién nos enseña que. la ciencia puede perfectamente curar-por métodos absolutamente seguros - a los pervertidos, ya sean innatos o que la desgracia los haya conducido a adquirir esas perversiones. Esto, hay que enseñarlo y deberá enseñarse, pero en Chile, solamente se dan estos conocimientos en mi clase universitaria, y en la Escuela de Altos Estudios del Museo Nacional. La Facultad de Medicina, y por uno que otro apóstol que empieza a dar conferencias, se interesó en exigir de los poderes públicos, para que esta enseñanza-a la manera como se da en los Estados Unidos, también se diera en Chile, como la conclusión de un trabajo o conferencia que yo mismo dicté en la Universidad de Chile y en la de Concepción. Sin embargo, esto duerme como otras notas de las muchisimas que no significan politequeria: aún más, alumnos hay en la Escuela de Altos Estudios, que no han podido obtener el permiso de sus autoridades respectivas, para asistir una sola vez por semana a las clases de Fisiología, aunque ofrecen compensar la hora o dos horas con su mismo trabajo. o con más trabajo: alumnos que pagarian con creces, porque irian a enseñar lo que más necesitan hoy sus educandos.

El espiritu criollo, del que Uds., hablan, se divisa también en la enseñanza: no se debe permitir que se enseñen los conocimientos que ellos mismos no procuran, y además, eso, no produce la notoriedad en que en ella fian para ascender. Construir, para los patriotas de verdad consistiria, en el territorio de la enseñanza, en usar de todas las diversas opiniones para edificar, con diferentes materiales sólidos 
un edificio. Refutar debería servir para construir, nó para destruir: pero. no vayamos tan lejos, miremos más de cerca y observemos a nuestros maestros que no educan: ellos creen que la misión del educador, debe ser grave, pero muy grave: no dejar que el alumno se acerque-como lo hace hoy el padre que considera a su hijo como un amigo. - Enseñar y lo más teóricamente, esa es su misión: educar. eso les restaria la divina gravedad. Pero habré de hacer excepciones al recordar a los Prolesores de la Universidad de Concepción. de la Escuela de Altos Estudios y a algunos de los Prolesores de la Universidad de Chile, en donde cada maestro es un verdadero padre de familia. Hay autoridades superiores de Instrucción Primaria que consideran impropia esta enseñanza, y aconsejan a algunas instituciones privadas de enseñanza no tomar como tales a alumnas educadas con conocimientos de Fisiología y de Ciencia Sexual; pero sigamos:

El cerebro del niño. fija,_como un timbre de goma se imprenta en un papel-todas las ideas que queramos grabarle, y si le ponemos diques a sus inclinaciones malsanas, éstos. quedan también grabados en su corteza cerebral. Son. por asi decirlo, pastas molúeables a nuestra voluntad; y si ni padres. ni maestros se ocupan de timbrar estos cerebros. los malos amigos serán sus profesores. Me imagino que Uds. me comprendan si les digo que dentro de nuestras cabezas nada está tranquilo: que cerebramos permanentemente, ¿en qué pensamos?en todo y aunque no queramos pensar; pero supongamos que arrojo en la sala 200 bolitas de piedra de esas que usan los pequeñitos para jugar: las lanzo con fuerza hacia donde ustedes están sentados: estas bolitas, representan las ideas que bullen en nuestro cerebro, ideas algunas malas, si Uds. quieren; pero, muchas de esas bolitas van a ser detenidas a pesar de la velocidad con que yo las he lanzado, en los pies de los asistentes o en los guarda-polvos de las murallas, o en las sillas, es decir encuentran un obstáculo, un dique y no seguirán: esos tropiezos. digo, son los diques que detienen la marcha o el avance de las bolitas; diques que llamaremos morales y que son verdaderas barreras para el avance de las ideas perversas. Podríamos mencionar, como tales, los consejos bien dirigidos; tratamientos de convicción que los médicos llamamos, sugestión despierta o psicoterapia. Estos diques, podrán formarlos: los padres que entienden sus deberes, los verdaderos maestros. los médicos. las religiones y el medio ambiente moral que les hayamos dado a nuestros hijos. Los hogares morales, son la grandeza de los paises; no iníporta que ellos sean pequeños, como lo es la Suiza; pero. el factor más importante es la mujer. Madre abnegada, hermana bondadosa. hija pura. novia ideal, ésto, es lo que educa al hombre y es lo único inconmovible y sublime que va quedando en el planeta: es ella, el elemento que da solidez al hogar: y la reunión de hogares forma la Patria. La mujer, es más propietaria de la tierra que el hombre, porque ella lo crea, lo cuida y lo educa. Los pueblos que se compenetran de estas verdades, van a la vanguardia del mundo. Todos recuerdan lo que vale una madre; y ésto. debe servirnos para saber apreciar a las demás. en cada señora que se atraviesa en nuestro camino y que puede ser otra madre, igual a la nuestra. A cada hombre le preocupa la honra de su hermana; entonces debemos cuidar de la honra de aquellas otras que, por una embriaguez amorosa. 
no merezcan en premio de su amor sincero, la villanía de una deshonra; un padre, que puede ser un hombre de alta cultura, desea purisima a su hija, y no deberia consentir, que una joven incauta, entusiasta del talento y enamorada de otras de sus dotes o de su fortuna, sea pasto de sus malas pasiones; el joven que anhela legitimas aspiraciones: honores, fortuna, hogar, deberá realizar los deseos de su alma, uniéndose con la mujer de sus ensueños y poesías, con la virgen inmaculada, a quién protegerá y que le servirá de estrella polar, de rumbo en su peregrino viaje y que también alumbrará y guiará a las demás mujeres, por muy debajo que estén sus condiciones sociales.

Asi como es ella. casta y pura, así también deben los jóvenes orientarse hacia la misma castidad; los que realizan esta virtud, tienen más cerebro, más energías, más carácter. Esto que digo. sin duda, hace reír a los libertinos; pero. la ciencia ha probado que las mismas exigencias sexuales que tienen las mujeres, deberian tenerlas los hombres, porque si ellas se conservan castas, igual exigencia debe hacérsele al hombre.

El alcohol, la Prostitución, esa repugnante instifución de venta de carne humana, es consentida por el Estado. Hoy, la brutalidad, la fuerza del hombre, impera. legisla sobre hombre y sobre mujer. y. sin consultar a ésta, ha inventado que él, no puede pasar sin dar satisfacción a sus placeres, aunque esa satisfacción sea prematura, antes que el fruto haya madurado; y es el Municipio el que les brinda la casa permitida; es él el que reglamenta y posee médicos que aseguran la sanidad, y en la cual casa, encontrarán repugnantes vicios y enfermedades que - no curadas - les llevará la desgracia hasta el sepulcro, y hasta la generación de sus hijos. Jamás se ha conseguido, con la prostitución permitida por la ley: sino acrecentar las enfermedades venéreas; aumentar la ociosidad de la juventud; estimular el vicio del alcohol y apagar en los jóvenes. los altos ideales de unirse a la mujer amada. Ha sido condenada esta institución en los pueblos cultos, y nosotros, los médicos, también la condenamos: pero, esa, es una hidra de mil cabezas, y no caigáis vosotros, jóvenes liberales, que profesáis la tolerancia y el respeto a la mujer. en autorizar este resabio de costumbres corrompidas. Abolición absoluta de la Prostitución y sin limitaciones, ese es el grito de los pueblos morales y a cuya cabeza va el médico que la condena como inútil, peligrosa y repugnante. No aceptéis la hipocresía de prostitución colectiva que es mala, al frente de prostitución de una, que es buena, porque esta trampa ya es conocida en todos los paises en que se ha batido la prostitución en éstos sus últimos reductos. Mirad la casa de la prostituta única, inscrita por el Municipio y reglamentada. es así: ésta toma una cocinera, una sirvienta de pieza y una portera para su servicio: las cuatro son del mismo linaje: es una casa con 4 prostitutas. que en un dia, pueden enviar a la ciudad confiada, 40 enfermos, mínimum de averiados, quizás para su vida entera. Y cuando se inscriben asiladas aisladas se tienen diez mil de esta estirpe (no hay número inferior de ellas en Santiago). Pues bien, como ninguna está sana, suministran 10 mil, a lo menos, de enfermos diarios. Qué fábrica más elocuente nos obsequian los Municipios y los interesados que subsista este sistemal $\mathrm{Y}$ los que se exitan en estos paraisos municipales, los 
que se burlan de la abstención. no querrán ver en ellos a miembros de su familia. - Soy liberal-honroso credo de mi vida_para admitir que. llevados de sus instintos, los jóvenes hayan trabado uniones, ilicitas; y para recordarles que, ya que su inexorable destino allá los llevó. sepan respetar a esa mujer. quien, quizás, en la génesis de sus sentimientos, estaba adornada de los más elevados ideales; pero que también, no olviden. que ella jamás vive tranquila tras el biombo ilícito, y que ni él tampoco jamás se expone a la luz. ¿Y no es mejor unirse legalmente?

Sólo, pues, el matrimonio es la única solución del problema.

Pero, dirá la juventud, el aguijón del instinto por un lado, y la exitación de novelas eróticas, biógralos y conversaciones malsanas, por otros, nos obligan a hundirnos en las casas de tolerancia. o a fa!tarnos el respeto a sí mismossimulando una tranquilidad sexual que no es sino un vicio. Entonces, también les daremos la mano, los curaremos, les enseñaremos la verdad. levantaremos. purificaremos. Sil Levantaremos a los caídos y no olvidemos nunca que Jesús. el más justo de los hombres, absolvió a María de Magdala.

El vicio secreto afecta el alma que se marchita y pierde el anhelo de buscar al sexo contrario: enfría los sentidos creadores y perturba el sistema nervioso originando serias neurosis: y fijaos bien. estas psiconeurosis ninguna deja de tener base sexual. Asi, entonces, tenemos elementos desorientados, flojos, frios contra el otro sexo, apáticos, enfermizos con base para la anemia, neurastenia. histeria y tuberculosis. Su solución, pues, es el matrimonio (y su curación es la psicoterapia) que, pese a quien pese, procura la castidad que aunque luese en algunos casos limitada-da calma. energía, salud y contento de vivir.

Nosotros que pretendemos monopolizar la instrucción, y si no somos capaces de procurar la educación sexual para concluir con un factor de degeneración: deberiamos estimular una libertad absoluta de enseñanza y en último caso. hacer una modificación profunda de los actuales métodos y del personal que hoy existe. Se pasa hoy desentendiéndose de la enseñanza de la ciencia de la vida y se tolera que los alumnos de la escuela. tengan esa enseñanza en los conventillos, en los corruptores de menores, en los muy sabidos, etc. Dejémosnos de oriflamas y de programa de partidos, mientras no le demos salud al pueblo. Gobernar: es dar salud a los conciudadanos, porque en sangre sana hay mente sana, mente sana dice orientación. disciplina, amor a la patria y horror a las convulsiones, a las revoluciones que no responden sino a la fuerza de las masas y a la guerra contra los intelectuales.

Existe un movimiento universal movido por los descontentos: hay una amenaza de esta naturaleza en todos los paises y desde hace más de 30 años; es un peligro que se cierne sobre todos nosotros, y en el que todos somos cómplices: movimiento que los impulsan los iletrados. los que no tienen responsabilidad, los que cuentan sólo con el número y que creen que es justicia mandar. porque son cantidad. Si en una familia de 10 hijos en formación, todavía inconscientes, permitiéramos que la casa se manejara por los 10 niños que comandaran sobre los dos padres. ICómo seria esa Babilonial ¿querrian esos 10 
niños pensar en el ahorro, en la previsión. en la economía financiera, en la distribución de los gastos y en la administración interna del hogar? Lo único plausible seria que, esos padres, educaran a sus 10 hijos; los hicieran trabajar y producir. distribuírles las responsabilidades y a los 25 años de edad. se empezaria a confiarles los bienes y las haciendas. Igualmente debemos pensar aqui: lo único útil que pueden hacer los partidos, es contribuir al progreso de la patria. educando muy bien a las masas con grandes diques morales y cuando estén bien instruídos, educados y madurados, permitirles la intervención en la cosa pública. Mientras tanto, preparémoslos nosotros; enseñémosles con el ejemplo: miremos, a los demás partidos. como otros tantos hogares que también se aman para el bien público, sin abdicar de que cada hogar debe desear ser mejor o igual a los mejores. Hagamos el vacio a aquellos que no se inspiren en los altos ideales de moralidad y que nos engañan con palabras. programas y teorias para que le sirvamos de pedestal, no en bien de la patria, sino en beneficio de ambiciones personales.

Las enfermedades sociales que invaden a nuestra raza, son tales, que ya no contamos sino como excepción los hombres que no ha contraído la blenorragia - la sífilis. Y ésto, no fuera nada si ellos sufrieran solos sus consecuencias; pero la trasmiten a su progenie. De aqui, resulta: que es proverbial aquello de que las escuadras extranjeras anuncian a sus tripulaciones, que los puertos de este país son focos de infección. Es incomprensible que los virus venéreos se extiendan por todas las poblaciones y que los municipios, gasten sumas ingentes en mantener ejércitos de empleados; en vigilar a la prostitución comercializada, y paguen médicos y enfermeras, cuando todo este enorme personal preparado. podría servir más eficazmente en sembrar al pais de Dispensarios.

El Dispensario de barrio, con médico, enfermera, laboratorio y medicina gratuitas es la única salvación que ha encontrado la ciencia para extirpar en absoluto, a los males sociales: como medio preventivo y curativo. todo lo demás es palabrería, y no responde a los consejos de la ciencia. Hay en el pais pocos Dispensarios que se dediquen a curar estas enfermedades; pero a ninguno se les ha suministrado los elementos suficientes para atender en la forma indicada iY son tan pocos los Dispensarios que existen que se cuentan con los dedos!

De un estudio que he debido hacer-estudio muy castigado, he encontrado que el minimum de enfermos atacados de males sociales, de sifilis, en Chile, es 400 mil: pero puedo decirles, que con los antecedentes recogidos, si se documentaran, un especialista neutral, un extranjero, no encontraria en la República menos de un millón. He propuesto el establecimiento de 105 Dispensarios de Tacna a Punta Arenas, para luchar durante 10 años. en el propósito de concluir con las enfermedades venéreas; Dispensarios que irian disminuyendo al acercarse al $100^{\circ}$ año y concluiriamos con no tener más que los actuales después da la lucha. Cuánto al gasto en los 10 años, no sería superior a 17 millones de pesos.

Si abandonamos la lucha y apreciamos que el hombre, que es el motor 
productor de la riqueza, valiera sólo $10 \mathrm{mil}$ pesos en Chile (en otros países se cotiza en 100 mil pesos) y sólo pusiéramos que el $10 \%$ muere a consecuencia de enfermedades venéreas, nuestros cálculos nos enseñan que perdemos 400 millones de pesos anualmente y en los 10 años, más de 5 mil millones de pesos ipor economizar 17 millones! Estos cálculos están basados en que Chile pierde por estas enfermedades 13,333 habitantes $(10 \%)$ de los 133.333 habitantes que mueren cada año, más el valor numerario que representan 400 mil enfermos que rinden menos en la producción del trabajo.

Pero, admirense más: todos los repartimientos públicos tienen una Dirección para manejarlos, hay un Código Sanitario que se ocupa de la sanidad y una sola cosa se olvidó: la de atacar a las enfermedades que producen la degeneración de la raza, las enfermedades venéreas. No hay ley, no hay disposición, ni reglamento que se ocupen de extirpar la sifilis y la blenorragia; pero hay reglamentos municipales que se ocupan de aumentar las enfermedades venéreas estimulando los focos de infección, como son las casas de tolerancia.

Los jóvenes cultos, no pueden ahogar las fuentes de la vida ni matar sus grandiosos ideales, asistiendo a las casas de tolerancia; ni tampoco, aceptar el camouflage de que se inscriban o reglamentar asiladas; individualmente. Deben rechazar las sugestiones, faltarse a sí mismos el respeto, destruyendo los órganos nobles que no les pertenecen a ellos únicamente. Queda la disyuntiva, o matrimonio, lo más temprano posible o la castidad igual que la que le recomendamos a las mujeres. De otro modo. la raza desaparece, porque no es vivir ser cadáveres vivientes.

Así como estamos dispuestos a unirnos todos: partidos, religiones, individuos y autoridades para repeler al enemigo que invadiere nuestras fronteras, asi también debemos asociarnos todos para repeler con energia al mayor de los enemigos, como son las enfermedades venéreas que roen a los más robustos de nuestros conciudadanos; males venéreos que son los causantes de la población de nuestras cárceles, de nuestros manicomios, que aumentan el alcoholismo. que fácilmente hacen crecer la mortalidad infantil, hasta amenazar con la disminución de la población que alborotan la sangre de los desorientados y bolcheviques que peroran pidiendo reivindicación, cuando lo que deberían pedir sería politicos preparados que los liberaran de los males sociales y programas de partidos, y que no tuvieran más que una sola inscripción: salud pública. Tenemos hoy, en el país. médicos, enfermeras, sanitaristas, estudiantes, sociedades filantrópicas e instituciones de Cruz Roja que forman un ejército abnegado y que no esperan más que un Estado Mayor y elementos, para emprender la lucha y colocar a la raza en un estado tranquilo y de trabajo. digna de merecer una situación envidiable capaz de colonizar y de propagarse para poblar los 300 mil kilómetros cuadrados de superficie que aún están baldios. Ser grande. no significa poseer un continente. ni decenas de millones de habitantes: basta con ser ilustrados, educados y sanos para que ningún obstáculo detenga el progreso de una nación. Nadie ha querido, jamás absorver a la Suiza que esté colocada en medio de los más poderosos paises de Europa, porque sus habitantes son ilustrados, educados y sanos: pero 
aumentan, y la población de Chile disminuye, a pesar de poseer la mayor natalidad que se conoce.

Yo, quisiera que la educación con instrucción sexual, se iniciara en los pequeñitos: aplicando la higiene personal. dándoles explicación simplista. pero absolutamente veridica, de los maravillosos fenómenos que ven en su vecindad. como la recundación de las plantas, la reproducción de los animales, etc.. lo que es una obra que exige el concurso de los padres. Esta primera enseñanza la daría la madre; de otro modo la inventa. exagera y la hace malsana la nodriza mercenaria. los empleados eróticos y aún los amiguitos. - que si no son seleccionados serán siempre enemiguilos-que enterrarán un puñal venenoso, cuya curación nadie prevee y que puede ser el punto inicial de un envenenamiento del alma y también de la muerte del cuerpo.

Si las madres iniciaran, todas, esta enseñanza. jamás mintiendo a los niños. tendrian como continuadora de sus obras a las maestras, que nunca deben actuar sino como actúan las madres; tiernas, benévolas. con tira y afloja. humanas, porque esos niños, son los hijitos adoptivos que la nación les confia.

Es. pues, en las escuelas primarias en donde esta clase de conocimientos se daria juntamente con las primeras letras. Muchísimo más serviria a la República. preparar al ciudadano a conocer con calma las funciones de su organismo: cómo trabaja el corazón, pulmones, cerebro, etc.. etc. y el desenvolvimiento paulatino y funciones de sus órganos creadores de vida. órganos que sólo ellos dan inmortalidad, que el de enseñarles análisis lógico, reglas de tres, idiomas, etc.

La educación sexual les da tranquilidad. les enseña a dominar sus instintos normales, a interesarse en crear en el porvenir conciudadanos sanos de espíritu y de cuerpo. La actual instrucción escolar les da una enseñanza sistemática y lo único que olvida es lo que verdaderamente les servirá en su vida: conocerse a sí mismo y saber lo que les ayudaría para ganar su pan. Esos alumnos más tarde serán obreros y ni se les enseña a cortar un adobe, a aserrar una tabla, a pintar una pared, a colocar un tornillo, ni a arar el suelo, a pesar de que las muy altisimas autoridades escolares saben que esos niños van a ganarse la vida como albañiles. carpinteros, pintores, mecánicos, agricultores, mineros, etc. A las niñas no se les enseña la higiene personal, menos todavía el saber retirar sin daño el polvo de sus casas, ni a coser, ni a hacer sus ropas, remendar medias, etc., y más tarde les exigiremos sean muy buenas dueñas de casa. limpias, hacendosas, económicas. Por otra parte. les exigimos se conduzcan con prudencia, recato. pudor; sepan cuidar su feminidad, sin jamás por jamás haberlas preparado en el conocimiento de sus funciones normales, en su magnífica evolución y en el grandioso llamado a ser la cuna de la humanidd; a dar la inmortalidad visible, porque ella no morirá nuncacontinuará su vida en su hijo. - Lo grande, lo sublime, lo inmortal, los fenómenos de la creación de un nuevo ser se tratan en el misterio. ocultamente, o no se tratan; y los misterios se adivinan con todo el cortejo de fantasías. Todavía más, para enseñar la moral sexual, se tiene el atrevimiento de hablar en forma despectiva y aún repugnante de los sagrados órganos, de aquellos que nos han hecho conocer la luz del dia. 
Las altisimas autoridades, pues, de la instrucción primaria, que hasta hoy andan tan elevadas, ya pueden acercarse a la tierra para enseñar estas Vulgaridades: la ciencia de la vida, que no la dominan; y lo que ellos no saben. no lo exigen. Llenaría demasiado sus complejos cerebros el dedicarlos a introducir las más útiles de todas las enseñanzas: tardarán no meses sino años en cons. truir programas. cuando con copiar cualquier folleto de lo que se enseña en los Estados Unidos, habria base para establecer ya una enseñanza seria. Pero. todo lo que signifique verdad o adelanto debe nacer de ellos, si nace de otro que no sea de su estirpe o partido, no es tomado en cuenta, no es consideradoRefutar, como lema patriótico debiera ser: aunar, ayudar con un elemento más para construir.

Y. a raiz de la idea de dar educación sexual, sinónimo de moralidad social. puede ocurrirsele a algunos esta idea: que el asunto se presta para crear algún circulo o influencia popular para fabricar adeptos. y entonces nacerá la casociación de moralidad, sliga co-sexual, , etc. etc.

En la instrucción secundaria. es peor aún: no existe todavia un cuerpo legislativo que de ella se ocupe directamenie. Y asi. los liceos son fábricas de almacenaje de memoria: quimica, física sin experimentación; estudios básicos como la Antropología. Etnologia, es decir, Pre-historia, esa base cientifica de la Historia no se enseña; Geología, nuestro suelo, base de la Química. Física. Minería. Agricultura, Farmacia, eso es snobismo, y además. la idea no ha nacido de ellos ¿para qué crear entonces esas asignaturas? ¿Y qué diré de la enseñanza de la Meteorologia que le sirve a diario al agricultor, al marino. al enfermo? etc. Nó, esas son novedades: clases de lujos. Estas clases que sólo se profesan en la Escuela de Altos Estudios, deberían estudiarla los candidatos a profesores de ciencias.

La instrucción secundaria no educa: los alumnos llegan a sus clases a oir conferencias y sabemos que de una enseñanza así, el $90 \%$ no asimila lo que produce el conferenciante; o también los oyentes se dan cita para comadrear. ahi. sobre otros tópicos, tópicos que muy bien conoce la Ciencia Sexual. Siendo así, no esperemos que se enseñe Fisiología e Higiene: y si alguno renombrado entra a esos terrenos, pasa sobre ellos como se pasa sobre el fuego, saltándolo. sin tocar las funciones de la reproducción y sin tocar el aseo personal por el uso del agua (que es tan barata). ¿Qué podemos, pues, exigirles a las madres de familia. cuando los maestros no dan enseñanza sobre los más altos deberes que conciernen a ellas, y a sus hijos. El a, b. c. de los derechos que una mujer, hoy día, trata de conquistar, debe ser: conocer las funciones de su vida. en especial de sus funciones propias; de la maternidad, de las bases cientificas para fijar la moralidad de sus hijas. Con estas bases. las ideas dadas por su pudor. y los suministrados por su religión son ayudantes eficaces.

Cuando la mujer conozca la Fisiologia y la Higiene, y cuando exija de los profesores sepan mirarlas como hijas y nó como mujeres. dándoles el respeto que merecen, de por si caerán-como caen los cuerpos pesados solicitados por la gravedad-en los demás derechos que tan injustamente se les niega. Y en- 
tonces, y sólo entonces, habremos separado el fantasma de la revolución, que en Chile será la del número contra la calidad: de la inmensa ignorancia contra la intelectualidad, porque la mujer, estabiliza el hogar, da los nobles ideales, el respeto a las respectivas autoridades, humaniza al hombre, y no habremos de olvidar que la suma de los hogares es la patria. También, ella, sabrá defenderse del libertino, que es en el campo de las ignorantes en donde ceba sus instintos: no olvidará que el amor del hombre, aunque impulsivo. Irágil, poligamo, que empieza por el instinto sexual, será educado por la que lo sabe así, para encerrarlo en una jaula de amor; para reducirlo con finura, atrayéndolo con tino, haciéndolo que se interese por el hijo de su alma.

Sin la mujer no tendría razón de ser de la existencia. Ella sabria que sla vida sexual es el cimiento de la creación, de la propiedad, de la familia: que despierta las cualidades altruistas: la abnegación. la ternura, la paciencia, la dulzura, el sentimiento del deber, el amor al prójimo y las elevadas comprensiones de la estéticas: pero aprenderá también que el inefable trastorno del amor. la coloca en un cielo de placeres intimos que le inhibe los sentidos, cuando está al lado del ser que adora, para cuidarse de no ceder ninguna caricia. porque en pos de ellas sólo el caballero-en la más alta comprensión de la palabra-la respetaria: Pero también, penetrada de amor platónico, ella enciende la hoguera de los instintos normales, latentes en el hombre y en ella misma, y amor con instinto es caida. Enseñarán a sus hijas que cel amor y la vida sexual con sus leyes - están en relación con los que gobiernan nuestro equilibrio individual psíquico y - lísico; así como con las leyes que dominan el equilibrio social; de lo que se - desprende, la evolución histórica de los seres y de los puebloss. Y deberá enseñarse para que esas hijas acondicionen su vida luchando con placer y entusiasmo en contra de los prematuros pedidos de sus instintos sexuales. Ese convencimiento le da más disciplina, la hace dueña de sí misma, como que dominando la carne, amplia su vigor, su pujanza e intelectualidad; en una palabra, le da salud. Y como decía Franklin: stodos nacemos con la lacultad, en una mano de poder alcanzar la salud y en la otra el poder de obtener riquezas.. Virtud de moral real da energías. y éstas dan riqueza; pero decir moral, es decir castidad verdadera, porque no es la castidad aparente la que da tranquilidad; hay que respetarse a si mismo. Es curioso pensar, que creerse serio, es tener satisfacción secreta de sus instintos: ¿qué mérito tendría esto?. El verdadero mérito lo da la lucha.

\section{Y pasemos a lo más grave.}

De las relaciones sexuales ilicitas nacen, por lo general, las enfermedades venéreas. La peor de estas relaciones es la cultivada en las casas de tolerancia.

Toda prostituta está contaminada antes de tres meses de la plaga azul: blenorragia, y antes de un año, del peor azote de la humanidad: la plaga roja, la sífilis. El General en Jefe en campaña en los Estados Unidos, durante la guerra mundial, evitó estas enfermedades suprimiendo la Prostitución. Los paises que no 
obraron así, fuvieron la recrudescencia más ormidable que jamás época alguna de la historia la ha tenido más espantosa. En todos los Estados de ese gran país ya no existe la Prostitución, de un modo directo o indirecto. Y en muchos Estados se castiga al que comele el crimen de contagiar; se vigila para que los cónyuges vayan sanos al matrimonio; se denuncia ante las autoridades a aquel que tiene la enfermedad y se hace guerra al prostituto y a la prostituta. En otros paises se recluye al contagiado para que esté libre de transmitir la enfermedad.

La sifilis es la productora de la inmensa mayoria de los abortos y de casi toda la mortalidad infantil; es, esta enfermedad. la más voraz de las comedoras de cerebro; ella puebla a los manicomios y a las cárceles; es la base para inyectar la tuberculosis y el cáncer: es la que envenena la sangre. dando origen a los desorientados, que nunca están contentos ni con la Patria ni con el hogar: y por otra parte aumenta la población de histéricos y pneurasténicos. El $80 \%$ de los hijos descendientes de sifiliticos, ignoran la plaga que los roe. Un $20 \%$ de hombres y un $40 \%$ de mujeres que tienen esta enfermedad la ignoran. Así, pues, no se curan los que no saben que tienen este mal. Chile está invadido de esta lepra: el $75 \%$ de nuestra población obrera de las pampas, de los puertos están enfermos, y sus hijos ńacen muertos o perecen al poco tiempo del más insignificante trastorno. El $30 \%$ de la población Irancesa, creía el profesor Fournier, estaba atacada de este mal; si esta ley fuera exacta, aquí tendríamos un millón $200 \mathrm{mil}$ enfermos. Si fuera el $20 \%$ como en Nueva York, tendriamos 800 mil. Pero yo quiero ser tan optimista que pongo $10 \%$ y tendriamos hoy 400 mil: pero que mañana, en un mes. serian el doble, o un millón. ¿y por qué? Porque el país carece de leyes, reglamentos y recursos para combatirlos. Recursos, leyes y reglamentos existirán mañana. dentro de un mes, si la salud pública fuera para los dirigentes tan importante como la política. El Código Sanitario, que nació por transacción, nació trunco, sin contemplar ni un solo inciso que se ocupe de estos males.

Tenemos un repartimiento público que se denomina Ministerio del Interior. y del que depende la Dirección de Sanidad; pero que no tiene tiempo para arbitrar los medios económicos a fin que el Código se cumpla. Tiene la Beneficencia, es decir, todos los Dispensarios y Hospitales del país. y la mayoria debería cerrarse por falta de recursos. Tiene mucho que hacer con enviar un Gobernador a cada Departamento para que den la hermosa tanda de estar permanentemente en peleas con el juez y demás autoridades: Gobernador que no sabe ni el número de escuelas de su Departamento ni lo que estudian en ellas. Son muchas veces buenos y vividores, y algunos sin control sobre sus pasiones. El que está habituado a una disciplina sexual, le es fácil disciplinarse en todas las energías. La energia es única y el que la malgasta en actividades sexuales, no puede ser capaz de otras actividades. La raza es horrorosamente sexual y de ahí, que siendo el país que tiene la mayor procreación de hijos es también el que tiene menos hijos, con el triste privilegio de poseer la mayor mortalidad infantil del mundo. En las clases de Higiene, en las de Estadistica y Demografía, así como en los Congresos médicos se exhibe en los Estados Unidos 
un termómetro que empieza con 10 (10 niños muertos por 1.000 de todas las edades) y Chile está en lo más alto del aparato con 225.

La falta de disciplina sexual hace que en Chile salga lo contrario; en el mejor clima de la tierra es donde hay más tuberculosos y heredo-sifiliticos. Los habitantes más proliferos del orbe amenazan con la despoblación de la República. Fiebre tifoidea, tifus exantemático, lues y mortalidad infantil nos colocan como los primeros del orbe. En ese mismo Ministerio a que nos referimos se tienen las divisiones políticas de la República, en tal forma, que da carcajadas a los extranjeros. Un ejemplo: el Departamento de San Fernando limita con la provincia de Santiago y con el mar y llega hasta Curicó y la cordillera; se extrecha en una cintura entre el río Chimbarongo y el Tinguiririca, de tal modo, que una piedra tirada del Departamento de Santa Cruz termina en el de Caupolicán pasando por encima del Departamento de San Fernando. La ciudad de Santa Cruz tiene un radio que podía comandar a las poblaciones situadas al Norte y al Oriente que están a su alrededor; y sin embargo, la ciudad misma pertenece parte al Departamento de Santa Cruz de la provincia de Curicó y otra parte al de San Fernando de la provincia de Colchagua. Pero, por no molestar a los ríos que la dividen, se molesta a los habitantes quienes tienen que recorrer grandísimas distancias cuando buscan la prolección de las autoridades y atraviesan por ciudades que podía favorecerlo si lueran cabezas de sus comunas.

En lugar de tantos errores, un Ministerio de Previsión Social, Sanidad y Beneficencia podría atender a la salud pública, teniendo en su radio la acción de Beneficencia, Hospitales. Dispensarios. Alcantarillado. Agua Potable y Sanidad, que es hoy la ocupación útil del Ministerio de lo Interior.

Pero, este, es un problema que interesa a los políticos: la creación de estos reparlimientos, no está en su Programa; asi como la creación de nuevos Departamentos y la rectificación de la Geografía Política. podría servir al bando contrario a sus aspiraciones. Seguirá la anarquia, predicción que la tiene estudiada ya la Ciencia Sexual.

Exisie un Ministerio de Hacienda, que tiene oficinas de aduanas y se ocupa - de tapar al país de papel moneda o de llegar al absoluto régimen del oro. sin embargo, el pais no tiene una oficina destinada a evitar la propagación de las enfermedades venéreas; y no podemos suprimir el inmenso papeleo lleno de verbosas frases de la lengua de Castilla, que nos ofuscan, cuando el único papel que debería gastarse sería el destinado para cada maestro a hacer el programa sobre educación sexual: esa sería la verdadera conversión de la moneda en oro.

Además, tenemos un Ministerio de Instrucción Pública, y si mañana se hiciera obligatoria la instrucción. no se encontrarian los suficientes maestros para enseñar tanto iletrado, y mejor que así sea todavía, porque la inmensa mayoria de las escuelas actuales no tienen las condiciones higiénicas para dar garantía a los educandos; en la promiscuidad humana con hambre y con frio, nace la tuberculosis. Yo quisiera que algún patriota hiciera una encuesta a las escuelas del país y examinara a los pequeñitos y vería cómo está propagada esta enfer- 
medad: ahora, si hiciéramos tal cual se ha hecho en los Estados Unidos, una investigación sobre el lado moral, veriamos la prematura sexualidad peligrosa y repugnante que domina a los educandos. Y veríamos, señores, también en una gran parte de los maestros. el desaliento, el poco estimulo y consideración y la nulidad de educación de Fisiologia que reciben de sus altisimas autoridades: ellos reciben alguna instrucción primaria, pero ninguna educación y si la llegan a poseer, es natural, pero no es técnica, adecuada al asunto que tratamos. En su repartimiento de Ministerio de Justicia, recordamos con horror las perversiones sexuales, pero muy repugnantes que dominan en las cárceles y que avergonzarian al corázón más empedernido que las presenciase.

¿El Ministerio de Industria y Obras Públicas nos hace pensar en un musulmán que con la pipa en la boca, mira impávido una representación del antiguo Imperio romano, que tenía como lema que los caminos son la base de la riqueza y la seguridad pública: y mirando el panorama de Chile. observaría que los caminos sirven como vericueto extratégico para los salteadores, no permitiendo que los pequeñitos afluyan a las escuelas desde 10 cuadras a la redonda. Este Ministerio tiene a su cargo secciones de insfrucción, revolviendo cntre rieles. puentes y canales, establecimiento de enseñanza secundaria y aún universitaria. El Instifuto Agronómico es de enseñanza universitaria y aún. cuando ahí se enseña ciencias y aplicaciones biológicas, la Fisiología y la Higiene son desconocidas, y son, precisamente, los futuros agricultores y los mayordomos de haciendas, los únicos que cuidarán en sus campos de la moralidad y de la salud de sus inquilinos. No es de extrañarse cuando en las Escuelas Normales y en el Instituto Pedagógico, establecimientos destinados a producir maestros en Biologia e Higiene, esos establecimientos, no poseen ni clase de Fisiología ni de Higiene, ni los servicios higiénicos adecuados.

Hay un Ministerio de Relaciones Exteriores y en él se sabe que en Panamá y en los Estados Unidos, han puesto cuarentenas en algunas ocasiones únicamente a los barcos de Chile. Ese Ministerio, entre los entretenimientos a que podía obligar a sus Ministros y Cónsules, sería utilísimo. el de exigirles una información documentada sobre el estado sanitario de los respectivos paises en los que sirven, y muy especialmente. lo relacionado a la Prostitución, a la moralidad escolar y al tratamiento de las enfermedades de trascendencia social y publicar esas informaciones, porque viniendo de importación nuestros gobernantes y cuerpos legislativos pudieran siquiera iniciar una campaña de salud pública.

Y el Ministerio de la Guerra, esponja absorvente de nuestro presupuesto. que desgraciadamente necesita no descuidarse, podría pensar, que la conscripción que lleva los mejores ciudadanos bajo la bandera debería ser extendido a mayor tiempo que el actual para evitar que los fuertes ejercicios militares no produzcan exagerado desarrollo muscular, que lleva al cansancio y a la tuberculosis, y recluir obligatoriamente, a todo el que sea contagioso venéreo hasta que no pueda trasmitir la enfermedad; y repartir a tadas las guarniciones. elementos completos de medicamentos, para que todo soldado pueda ser tratado gratuitamente por un periodo mínimum de tres años; y obligar a la desinfección obligatoria a 
todo individuo que regrese al cuartel para que no se desarrollen en ellos tales enfermedades, es decir, enseñar una educación sexual en toda unidad. Esto, deberia hacerlo antes que invertir en cañones, porque aunque faltaren aquellos. cuando se tienen ciudadanos sanos de espíritu y de cuerpo, a falta de armamento, pero con brazos vigorosos. las galgas de los Andes como armas bastarán’.

El Parlamento Nacional. tan especializado en derrivar Ministerios, en ocupar la milad de su tiempo en la calificación de poderes-aunque hay un Tribunal especial destinado a ello y que han querido transformarlo en un verdadero Ateneo Literario para que lo oigan no los lectores, que siempre no los han tenido. sino donde ellos desean predominar, iy que ojalá fuera siquiera para presentarle una corona de triunfos al ideal de su vida!, no se ocupará en crear. no digo una sección de Higiene. de Previsión Social y de Beneficencia. sino que ni aún una oficina para atacar a las enfermedades que degeneran a nuestra raza, que disminuyen nuestra población y destruyen la fuente de producción. que es el motor humano. Sin esperar siquiera que de estos temas se ocupen. digo yo, que no contemos con él, prescindamos de él como ya el pais lo está verificando, tratemos nosotros de convencer ciudadano por ciudadano: a los padres, a los maestros, a los alumnos, el de procurarse una educación sexual inculcando los sentimientos de moralidad y caballerosidad. convenciendo hasta el último obrero del. último conventillo, de no ir al matrimonio sino sano para así poder engendrar hijos sanos, porque en las tareas de la vida cada hijo de esos equivaldrá a dos motores de los actuales. Inculquemos a la mujer el que no se fie nunca de los hombres. no porque sean malos, sino porque sus impulsos de varones y su educación dominadora, el mal ambiente y las malas costumbres arraigadas en la sociedad. los hace peligrosos. pero digámosles también que ellos son débiles, que se les puede educar en sentimientos de caballerosidad, que se les puede amarrar con cadenitas de ternura. invocándoles al recuerdo de su madre, de sus hermanas y de sus futuras hijas. A los hombres intelectuales. que han desarrollado su cerebro y que están dedicados a dirigir masas de hombres. a esos, digámosle que su responsabilidad es enorme $y$, que deben orientarse a sus subordinados por la linea recta que es la más corta que existe entre dos puntos. $Y$ cuando ellos manejen mujeres ya sean obreras, dactilógrafas o alumnas, tengan el respeto que la necesidad, la pobreza y el estado indefenso de la mujer les exige y no tomarlas como objetos de simple entretenimiento o como esclavas blancas: que no deben usar términos que puedan producir ofensa moral ante sus alumnas. las cuales, no deben ni pueden ser otra cosa que sus hijas. ¡Cuántas disiluciones hemos tenido en algunas ocasiones al contemplar que hombres que por su influencia o su situación han olvidado que tienen hijas, hermanas y esposas!

La Ciencia Sexual dice que: los que tienen creencias religiosas tienen también una moral sexual que ayuda; pues, entonces, mirémoslos con gran respeto. Pero los que no tienen creencias religiosas y han orientado su moral guiados por su herencia. por el medio ambiente bueno y por su educación cientifica. 
también cumplen con los preceptos de moralidad. Como se ve. se podría deducir de esto que: la moral es una. venga de donde viniere.

Pues bien, aquellos que se hayan colocado diques morales por religiones y por creencias han sumado sus esfuerzos.

Pero. no nos preocupemos tanto del Estado-providencia del que de este pais tanto se espera. ni de la indeferencia de aquellos a quienes eso no les interesa, ni mucho menos de aquellos que se rien de tan grandes problemas. Es muy común observar en la gente de espiritu criollo. ambiciosos sin base. egoistas que sueñan con glorias, burlarse de toda proposición que de ellos no haya nacido. usando ya la ironía, o de cuchufletas para aminorar reputaciones y empresas de espíritu público que ellos no hayan conseguido. No conciben sino lo que de ellos o de su circulo nazca y que a ellos sirva. (y siempre que temen que el autor sobresalga). Este espiritu domina también tanto a instituciones educacionales como en sociedades comerciales: bizantinismo y bolcheviquismo. Propongan Uds. una acción utilisima para concluir con la mortalidad infantil que es la más alta que en el mundo existe. resultante de la herencia sifilitica y declaren Uds. que por ser el $80 \%$ de la raza rusa sifilitica han sobrevenido las más espantosas convulsionss, asesinatos de intelectuales y a los más grandes crimenes de que recuerda la Historia y que por lo tanto, quisiéramos concluir con la hidra que nos amenaza. en nuestro país. por las mismas causas y agreguen que por esta misma razón. no podriamos permitir que las masas no ilustradas dominen por la cantidad y reflexionen que es un asunto baladi por el instante histórico el ser radical, conservador o liberal, religioso o irreligioso. colrade masónico o cofrade beatísimo y digan que lo único prácticu y decisivo es tener raza sana: propongan que los problemas de salud pública se reduzcan sólo a dos: Educar dándole gran importancia a la educación sexual, y sembrar de Dispensarios en el pais para desarraigar las enfermedades y verían Uds. entonces las contestaciones:

- Pero estas ideas no han sido propuestas por el Partido Radical, (que domina en el pais $y$ ha rehuido formar gobierno).

- El Partido Liberal, que es de centro. y del único del cual debe salir el Presidente de la República, no lo ha inscrito en su Programa.

-.El Partido Demócrata. que tiene masas, aunque no preparadas para dirigir, no ha comprendido el problema y por tanto no naciendo de sus dirigentes, ni produciendo esto una independencia económica a sus miembros no les interesa el problema. Sin embargo debo ser sincero, diciendo que la clase de obreros está sedienta por saber y por curar los males que les aquejan. En lugar de flamear banderas, discursear y empujar para arriba a sus prosélitos que luego los olvidan, deberian tener como única obsesión el Dispensario con médico, enfermera y medicina gratis a fin de extirpar sus males venéreos.

- El Partidor Conservador diría de estos asuntos de alta moralidad. eque son impúdicos y que es mejor que venga el castigo ede Dios sobre tanto enfermo de vicioss. Y como ellos no son asexuados, les recordaré que la sifilis no es más vergonzoza que tener tuberculosis. que la sifilis no respeta hogares y que el 
$20 \%$ de los hombres, el $40 \%$ de las mujeres que han adquirido la sifilis y el $80 \%$ de los hijos de sifiliticos, ignoran el que son victimas de esta enfermedad. Que una gran cantidad de enfermedades del corazón, del cerebro y de las llamadas enfermedades difíciles e incomprensibles, nacen de las sifilis, que la inmensa mayoría de los abortos, de la mortalidad infantil, de las pneurosis, de las mutilaciones en la mujer son de origen venéreo.

$\mathrm{Y}$ asi, como en Francia, durante la gran guerra, apesar de que los políticos habian anarquizado el pais, se levantó el alma nacional como una potencia vigorosísima y afrontó la lucha con energia desgastando la sangre de sus mejores hijos-para defender su patria,-asi también nosotros no esperemos nada sino de nuestra alma nacional y eduquemos a la madre en el hogar. a la maestra en la escuela, establezcamos Dispensarios: pidámosles Dispensarios a los Bancos. Clubs. Cajas Hipotecarias y de Ahorros, a las Fábricas, a las Industrias Mineras, a los Hacendados, a los Municipios, y levantemos banderas con esta sola divisa: patria es salud pública.

DR. EDUARDO MOORE.

12 de Julio de 1924. 